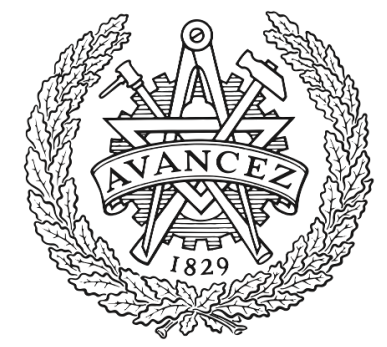

CHALMERS

UNIVERSITY OF TECHNOLOGY

\title{
High gain V-band planar array antenna using half-height pin gap waveguide
}

Downloaded from: https://research.chalmers.se, 2023-04-26 09:52 UTC

Citation for the original published paper (version of record):

Taghikhani, P., Yang, J., Vosoogh, A. (2017). High gain V-band planar array antenna using half-height pin gap waveguide. 2017 11th European Conference on Antennas and Propagation, EUCAP 2017: 2758-2761. http://dx.doi.org/10.23919/EuCAP.2017.7928269

N.B. When citing this work, cite the original published paper. 


\title{
High Gain V-Band Planar Array Antenna Using Half-Height Pin Gap Waveguide
}

\author{
Parastoo Taghikhani ${ }^{1}$, Jian Yang ${ }^{2}$, Abbas Vosoogh ${ }^{3}$, \\ ${ }^{1}$ Dept. of Electrical Engineering, Amirkabir Univ. of Technology, Tehran, Iran, taghikhani@aut.ac.ir \\ ${ }^{2}$ Dept. of Signals and Systems, Chalmers Univ. of Technology, Gothenburg, Sweden, jian.yang@chalmers.se \\ ${ }^{3}$ Dept. of Signals and Systems, Chalmers Univ. of Technology, Gothenburg, Sweden, abbas.vosoogh@chalmers.se
}

\begin{abstract}
With growing demand for mm-Wave applications, gap waveguide technology introduced many advantageous features compared to hollow waveguides or SIW. Till now several wideband, high-efficiency and highly directive planar gap waveguide antennas have been proposed. Recently, a new form of pins, the so called half-height pin, is proposed for realizing gap waveguide technology. In this paper, a wide-band, high gain, and high efficiency $8 \times 8$-element slot array antenna for $60 \mathrm{GHz}$ band based on the new form of pins is introduced. The simulation shows a very good performance of the antenna, with $14 \%$ bandwidth of the $10 \mathrm{~dB}$ return loss, $26 \mathrm{dBi}$ realized gain and close to $80 \%$ aperture efficiency. The antenna has less difficulty in manufacturing because of new pin form and therefore is suitable for the low cost mass production of mm-Wave antennas.
\end{abstract}

Index Terms-gap waveguide, half-height pin, planar slot array.

\section{INTRODUCTION}

The rapidly growing demands for high data rate communication systems leads to usage of higher frequency bands. Recently the $60 \mathrm{GHz}$ band is very attractive due to the huge unlicensed bandwidth (up to $7 \mathrm{GHz}$ ) available worldwide [1]. One of the challenges for mm-Wave wireless systems is to develop a highly directive planar antenna with high aperture efficiency.

Substrate Integrated Waveguide (SIW) and microstrip arrays are candidates for mm-Wave planar antennas with low profile. However, because of dielectric losses at mm-Wave frequencies they have low aperture efficiencies [2], [3]. Waveguide slot arrays are high efficiency antennas which do not suffer from dielectric losses. However, corporate feed networks in wideband waveguide slot arrays are so complicated and bulky that at mm-Wave frequencies the manufacturing process is very complicated and expensive [4], [5].

The newly introduced gap waveguide technology is a promising way to design a high-gain and high-efficiency planar slot array antenna for mm-Wave applications [6]-[11]. Low cost manufacturing process of gap waveguide technology compared to hollow wide-band waveguides antennas at mmWave frequency bands is a considerable advantage. No need for electrical contact between antenna layers solves many fabrications problems, especially in the mass production of the antenna.

In gap waveguides, PEC-PMC (Perfect Electric ConductorPerfect Magnetic Conductor) parallel plate waveguide creates a stop band while a textured surface, such as the bed of the nails or mushrooms, realizes a PMC plate. The textured surface incorporates a guiding structure that can be a ridge, groove or strips. Thus gap waveguides can be categorized into three forms [12]-[15]. The PMC surfaces are usually of a quarter wavelength texture of pins which can achieve a wideband performance. The gap between two plates should be smaller than a quarter of the wavelength to prevent any wave propagation in the gap so that the waves can be propagated only along the guiding structure such as a ridge.

Molding and die pressing or die-sink Electrical Discharge Machining (EDM) are the methods of fabrication gap waveguide Components among other manufacture technologies. The shape of pins in the textured surface of a gap waveguide can be different but the pins length should be always close to a quarter wavelength long. Recently a new form of pins, called as the half-height pins with a height of an eighth wavelength is proposed [16]. Half-height pins have approximately the same stop bandwidth and performance as the full height ( quarter wavelength) pins, and because of shorter length, the fabrication of this type of pins is less expensive, especially for mass production goal.

Thus gap-waveguide components such as antenna arrays, couplers and filters [17]-[21], or packaging structures [22] can be redesigned with the new half-height pins with little efforts. In [16] and [23] the idea of half-height pins has been verified for a bend transmission gap-waveguide line.

In this paper, an $8 \times 8$ planar slot array antenna based on half-height pins gap-waveguide technology for $60 \mathrm{GHz}$ is proposed. For corporate feed network, ridge gape-waveguide with half-height pins is designed. In distribution network layer half-height pins are located on both the upper and the lower plate but the ridge locates only in the lower plate.

First, a $2 \times 2$ sub-array antenna is designed and simulated in an infinitely large array environment. Then, it is extended to a $4 \times 4$ sub-array with a 4 -way corporate feeding network and complete $8 \times 8$ slot array antenna is finalized in the last step. The slots shape of the final antenna has been modified optimally for manufacturing. Although, the antenna is still composed of three unconnected layers as the previous antenna with the full-height pins, the new half-height pins reduce the difficulty of fabrication. 


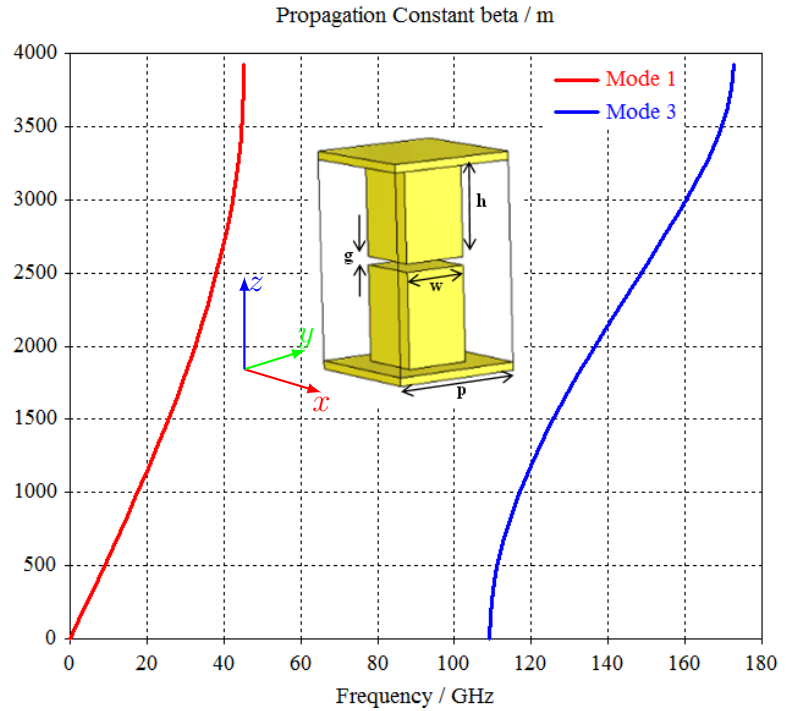

Fig. 1. Unit cell for half height pin and its simulated stop band.

TABLE I

Dimensions of $8 \times 8$-ELEMENT ARRAY ANTENNA PROTOTYPE FOR MANUFACTURING

\begin{tabular}{llc}
\hline \multicolumn{1}{c}{ Component } & \multicolumn{1}{c}{ Parameter } & Value $(\mathrm{mm})$ \\
\hline \multirow{3}{*}{ Outer Radiating Slot } & Length & 2.75 \\
& Width & 2.3 \\
& Depth & 0.5 \\
\hline \multirow{3}{*}{ Inner Radiating Slot } & Length & 2.6 \\
& Width & 1.0 \\
& Depth & 0.5 \\
\hline \multirow{3}{*}{ Top Layer } & Thickness & 1.58 \\
& Length & 40 \\
& Width & 40 \\
\hline \multirow{3}{*}{ Coupling Slot } & Length & 2.79 \\
& Width & 0.9 \\
Middle Layer & Depth & 1.0 \\
\hline Bottom Layer & Thickness & 2.23 \\
\hline \multirow{2}{*}{ Corporate feed Ridge } & Thickness & 4.0 \\
\hline \multirow{2}{*}{ Feed Waveguide } & Width & 1.0 \\
& Height & 1.3 \\
\hline \multirow{4}{*}{ Pin } & Length & 3.8 \\
& Width & 1.9 \\
\hline & Width $(W)$ & 0.4 \\
& Air Gap $(g)$ & 0.05 \\
& Pin Period $(p)$ & 0.8 \\
& Top Part Height & 0.66 \\
& Bottom Part Height & 0.57 \\
\hline
\end{tabular}

\section{Half Height Pin Gap-Waveguide}

Fig. 1 shows a half-height pin unit cell configuration. As it is named, pin length is only one eighth wavelength long, a half of the previous full-height pin. As there is an air gap between the upper and the lower pins, two plates are not electrically connected. The length of the pin is denoted by $h$. Pin width and the gap are $w$ and $d$ respectively. The pin periodicity is $p$ in both $x-$ and $y$ - direction.

The Eigen-mode solver in CST Microwave Studio has been applied to this basic unit cell of the half-height pin configuration for obtaining the stop-band characteristics. The dispersion diagram of the infinite pin array is shown in Fig. 1. The stop-band is approximately from $45 \mathrm{GHz}$ to $110 \mathrm{GHz}$. Antenna feeding network is in the form of ridged gap

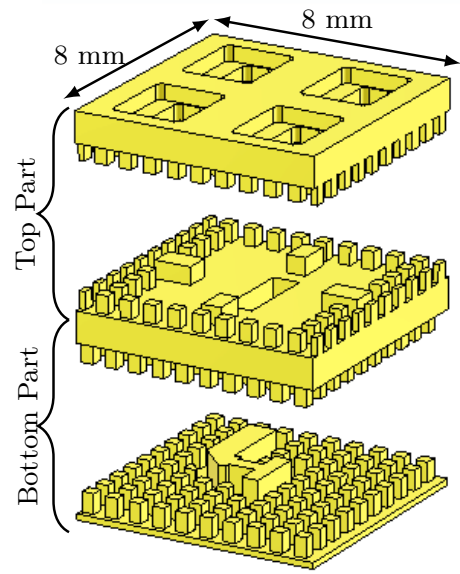

(a)

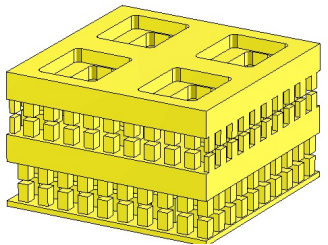

(b)

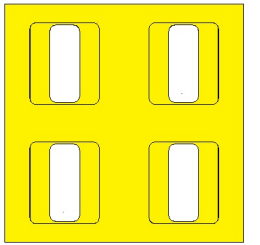

(c)
Fig. 2. a) Three layers of $2 \times 2$ sub-array antenna configurations, b) the unit cell, and c) the top view

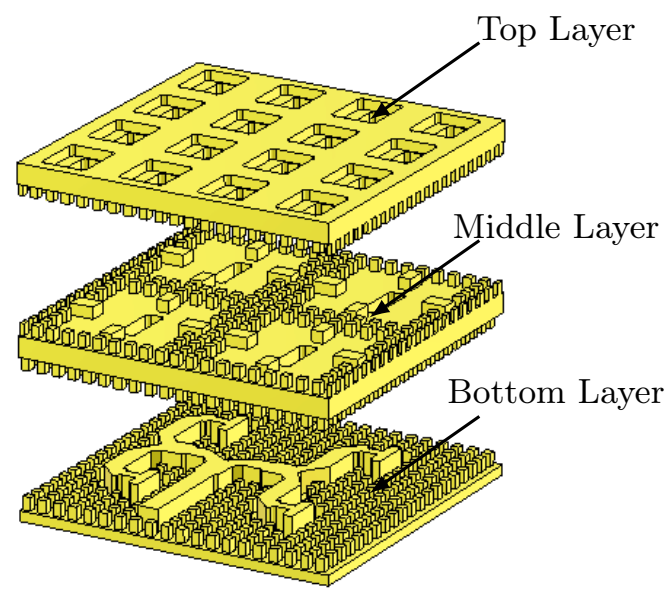

Fig. 3. $4 \times 4$ slot sub-array configuration with 4 -way corporate feeding network.

waveguide. A single ridge is located on the bottom layer and double pins placed on both plates. Pin dimensions are listed in Table I.

\section{CAVITy BACKed Slots Sub-ARray}

Antenna geometry consists of two parts. The bottom part is the part of the corporate feeding network and the top part is the cavity backed slot array.

Initially a $2 \times 2$ sub-array, as shown in Fig. 2, is designed and optimized in the infinite array environment by using CST Microwave studio. A T-shaped impedance matching sections is added to obtain better coupling between power divider network and slot array, and consequently to improve the reflection coefficient of the antenna.

As we use infinite array approach, mutual coupling between sub-arrays included in the results. Therefore, the simulation can be a good approximation of the final antenna performance. The slots spacing and dimensions are optimized to achieve high possible gain with consideration of grating lobes prevention. 


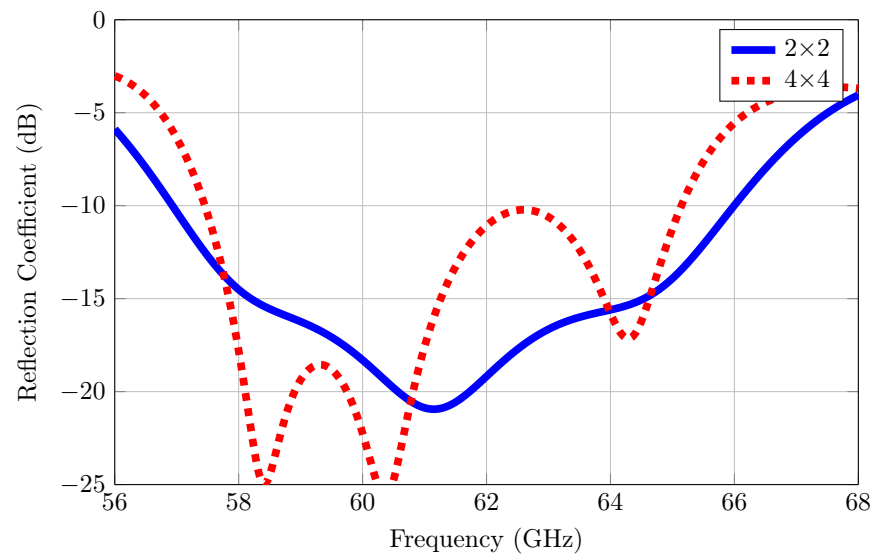

Fig. 4. Simulated reflection coefficient for the $2 \times 2$ and the $4 \times 4$ slot subarray.

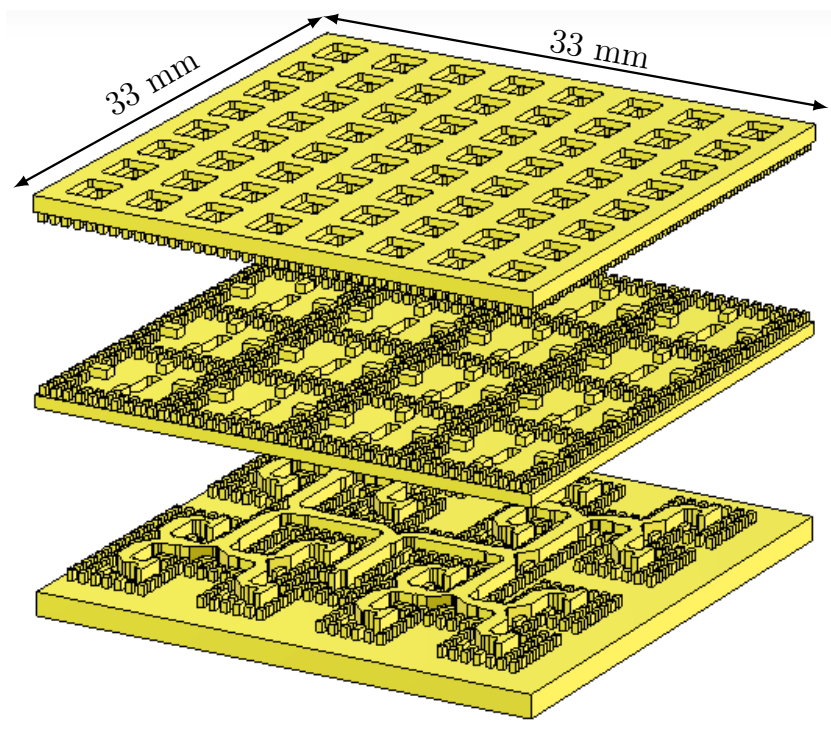

Fig. 5. Geometry of planar $8 \times 8$-element slot array antenna.

The height of the radiating slots has been increased in this design compared to the full-height pin design due to manufacturing restrictions on the thickness of the top layers. A thicker depth of the slots degrades reflection coefficient performance while a thinner layer is hard to manufacture.

After designing a $2 \times 2$ sub-array, a 4 -way corporate power divider is designed and the antenna extended to a $4 \times 4$ slot array antenna. Fig. 3 shows the $4 \times 4$ antenna sub-array. Full wave simulation has been applied and the results of both the $2 \times 2$ array and the $4 \times 4$ array are illustrated in Fig. 4 .

\section{IV. $8 \times 8$ Planar Slot Array Antenna CONFIGURATION}

Fig. 5 shows the final antenna configuration, which consists of three unconnected layers. In the bottom part, power divider is implemented in the form of the half height pin ridge gapwaveguide. the mid-layer contains half top pins of feeding network and half bottom pins of cavity backed slots layer. The top layer also has slots and top half pins of the cavity part.

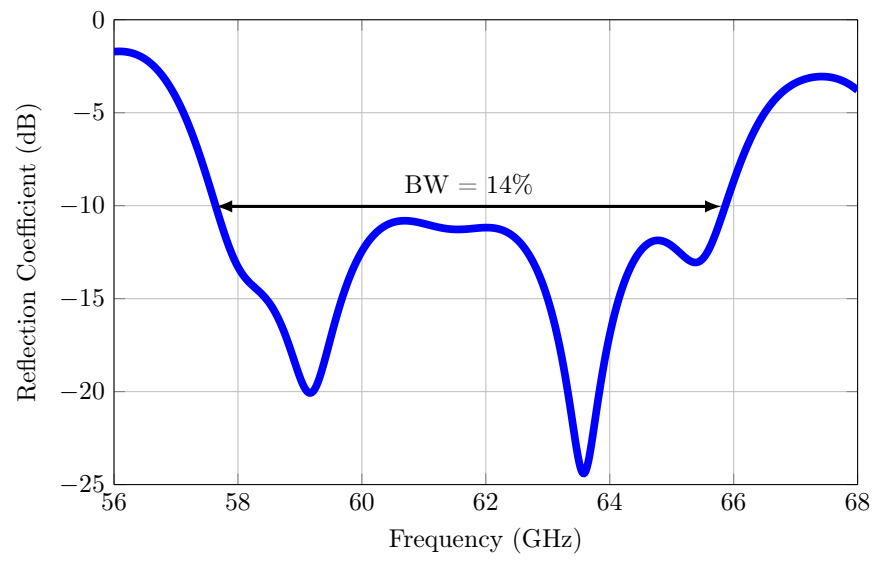

Fig. 6. Simulated reflection coefficient of final $8 \times 8$ antenna.

The total size of the antenna is $33 \times 33 \times 7.8 \mathrm{~mm}^{3}$. The final antenna has a fewer number of pins in distribution feeding network part which is beneficial for manufacturing and mass production of the antenna.

The final antenna reflection coefficient is shown in Fig. 6 and the antenna exhibits an impedance bandwidth (VSWR $\leq 2)$ of $14 \%$ from 57.5 to $66 \mathrm{GHz}$.

The full wave simulated radiation patterns of the antenna at 58, 62 and $66 \mathrm{GHz}$ in the $E-$ and the $H$-planes are plotted in Fig. 7. The radiation patterns are symmetrical and the first sidelobe levels in both $E-$ and $H$-planes are around $-13 \mathrm{~dB}$.

Fig. 8 depicts the directivity and the realized gain of the antenna versus frequency. The dashed straight lines show the maximum available directivity of an aperture with the dimension of $33 \times 33 \mathrm{~mm}^{2}$ when the aperture efficiency is $60 \%$ to $90 \%$.

The antennas parameters are listed in Table I. Pins in both parts have the same size except for their heights.

\section{CONCLUSion}

A planar slot array antenna with corporate power divider based on half-height pin gap-waveguide technology for V-band applications is introduced.

As long as any electrical connection between antenna layers is not required it has less complicated fabrication process. Half-height pin adds additional benefits of having shorter pins for easier manufacturing. The half-height pin antenna shows good performance. Simulated realized gain is close to $26 \mathrm{dBi}$ over the entire operation bandwidth from 58 to $66 \mathrm{GHz}$ and the total radiation efficiency is higher than $75 \%$. New fabrication methods such as die-sink EDM or die forming can provide us low cost $\mathrm{mm}$-Wave antenna for $5 \mathrm{G}$ application.

The new form of pins is promising for gap waveguide slot array antennas though for larger antennas the air gaps in the middle of pins may result in slight more attenuation.

\section{ACKNOWLEDGMENT}

The authors acknowledge the deceased Professor Per-Simon Kildal, for his helps and ideas during the research. 


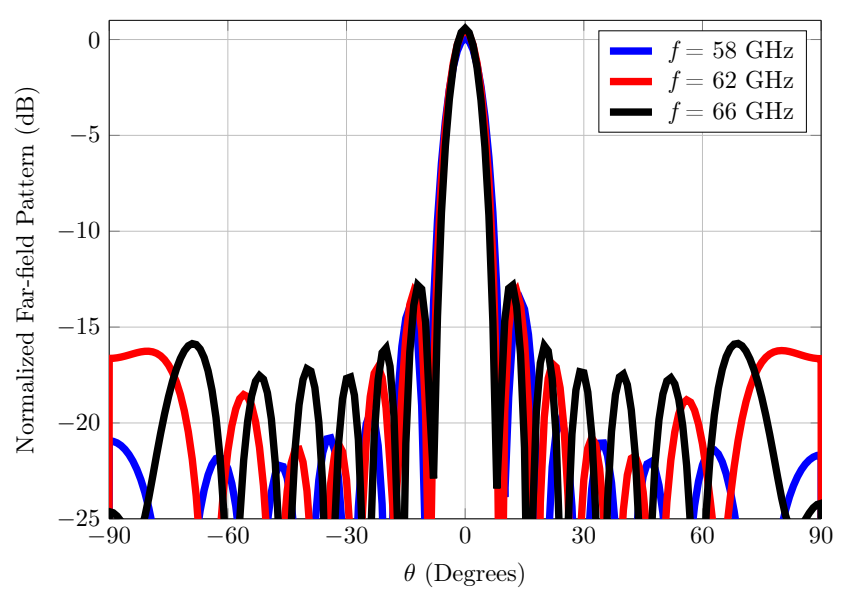

(a)

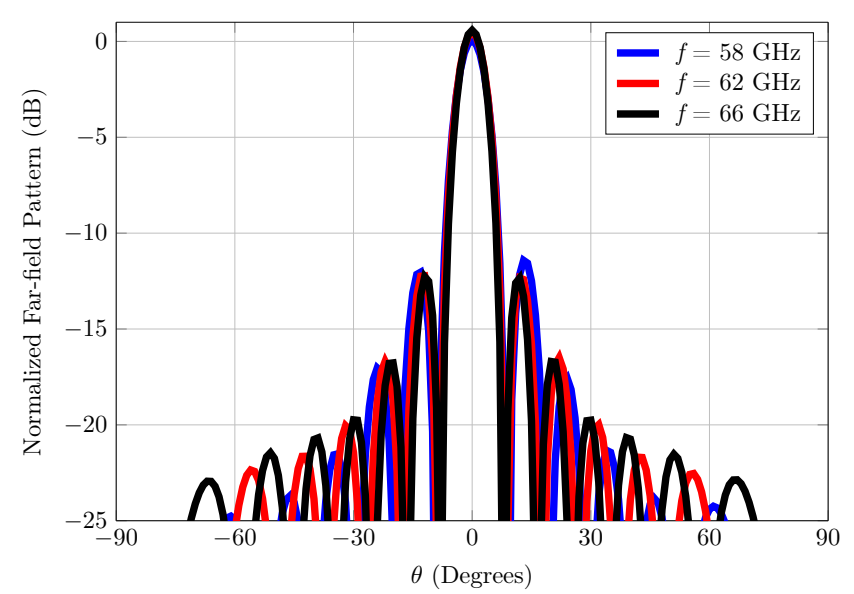

(b)

Fig. 7. Radiation pattern of $8 \times 8$-element slot array antenna in the a) $E$-plane, and b) $H$-plane.

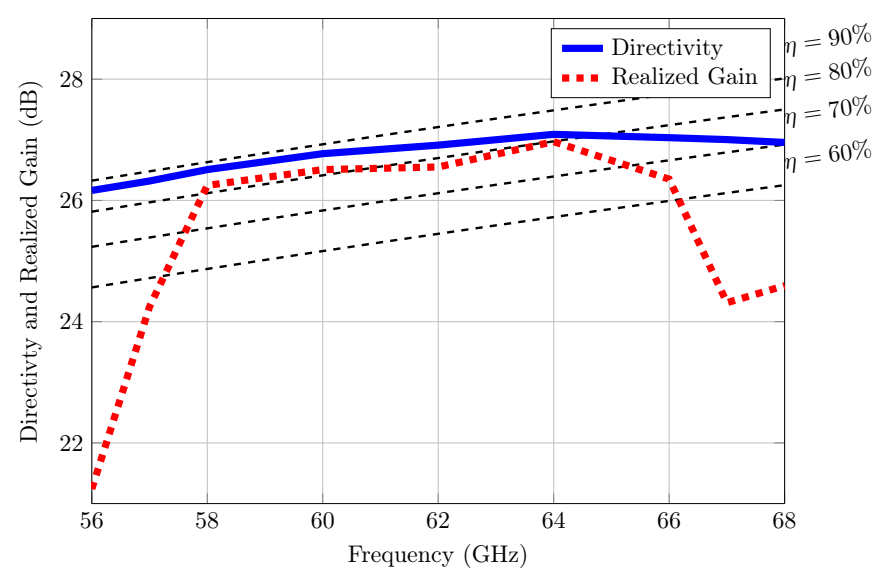

Fig. 8. Directivity and realized gain of simulated antenna.

\section{REFERENCES}

[1] S. K. Yong and C.-C. Chong, "An overview of multigigabit wireless through millimeter wave technology: potentials and technical challenges," EURASIP Journal on Wireless Communications and Networking, vol. 2007, no. 1, pp. 1-10, 2006.

[2] Y. J. Cheng, Y. X. Guo, and Z. G. Liu, "W-band large-scale high-gain planar integrated antenna array," IEEE Transactions on Antennas and Propagation, vol. 62, no. 6, pp. 3370-3373, 2014.
[3] J. Wu, Y. J. Cheng, and Y. Fan, "A wideband high-gain high-efficiency hybrid integrated plate array antenna for v-band inter-satellite links," IEEE Transactions on Antennas and Propagation, vol. 63, no. 4, pp. 1225-1233, 2015.

[4] Y. Miura, J. Hirokawa, M. Ando, Y. Shibuya, and G. Yoshida, "Doublelayer full-corporate-feed hollow-waveguide slot array antenna in the 60ghz band," IEEE Transactions on Antennas and Propagation, vol. 59, no. 8, pp. 2844-2851, 2011.

[5] D. Kim, J. Hirokawa, M. Ando, J. Takeuchi, and A. Hirata, " $64 \times 64$ element and $32 \times 32$-element slot array antennas using double-layer hollow-waveguide corporate-feed in the $120 \mathrm{ghz}$ band," IEEE Transactions on Antennas and Propagation, vol. 62, no. 3, pp. 1507-1512, 2014.

[6] A. U. Zaman and P.-S. Kildal, "Wide-band slot antenna arrays with single-layer corporate-feed network in ridge gap waveguide technology," IEEE Transactions on Antennas and Propagation, vol. 62, no. 6, pp. 2992-3001, 2014.

[7] E. Pucci, E. Rajo-Iglesias, J.-L. Vazquez-Roy, and P.-S. Kildal, "Planar dual-mode horn array with corporate-feed network in inverted microstrip gap waveguide," IEEE Transactions on Antennas and Propagation, vol. 62, no. 7, pp. 3534-3542, 2014.

[8] M. Al Sharkawy and A. A. Kishk, "Wideband beam-scanning circularly polarized inclined slots using ridge gap waveguide," IEEE Antennas and Wireless Propagation Letters, vol. 13, pp. 1187-1190, 2014.

[9] A. U. Zaman and P.-S. Kildal, "A new $2 \times 2$ microstrip patch subarray for $60 \mathrm{ghz}$ wideband planar antenna with ridge gap waveguide distribution layer," in 2015 9th European Conference on Antennas and Propagation (EuCAP). IEEE, 2015, pp. 1-4.

[10] D. Zarifi, A. Farahbakhsh, A. Zaman, and P.-S. Kildal, "Design and fabrication of a high-gain $60 \mathrm{ghz}$ corrugated slot antenna array with ridge gap waveguide distribution layer," IEEE Transactions on Antennas and Propagation, vol. 64, no. 7, pp. 2905-2913, 2016.

[11] A. Vosoogh and P.-S. Kildal, "Corporate-fed planar $60 \mathrm{ghz}$ slot array made of three unconnected metal layers using amc pin surface for the gap waveguide," IEEE Antennas and Wireless Propagation Letters, p. Unpublished, 2016.

[12] P.-S. Kildal, E. Alfonso, A. Valero-Nogueira, and E. Rajo-Iglesias, "Local metamaterial-based waveguides in gaps between parallel metal plates," IEEE Antennas and Wireless Propagation Letters, vol. 8, pp. 84-87, 2009

[13] P.-S. Kildal, "Three metamaterial-based gap waveguides between parallel metal plates for mm/submm waves," EuCAP 2009, 2009.

[14] H. Raza, J. Yang, P.-S. Kildal, and E. A. Alós, "Microstrip-ridge gap waveguide-study of losses, bends, and transition to wr-15," IEEE transactions on microwave theory and techniques, vol. 62, no. 9, pp. 1943-1952, 2014

[15] H. Raza, J. Yang, P.-S. Kildal, and E. Alfonso, "Resemblance between gap waveguides and hollow waveguides," IET Microwaves, Antennas \& Propagation, vol. 7, no. 15, p. 1221, 2013

[16] F. Fan, J. Yang, and P.-S. Kildal, "Half-height pins-a new pin form in gap waveguide for easy manufacturing," in 2016 10th European Conference on Antennas and Propagation (EuCAP). IEEE, 2016, pp. 1-4.

[17] J. Yang and H. Raza, "Empirical formulas for designing gap-waveguide hybrid ring coupler,' Microwave and optical technology letters, vol. 55, no. 8, pp. 1917-1920, 2013

[18] M. S. Sorkherizi, A. Khaleghi, and P.-S. Kildal, "Direct-coupled cavity filter in ridge gap waveguide," IEEE Transactions on Components, Packaging and Manufacturing Technology, vol. 4, no. 3, pp. 490-495, 2014.

[19] E. A. Alós, A. U. Zaman, and P.-S. Kildal, "Ka-band gap waveguide coupled-resonator filter for radio link diplexer application," IEEE Transactions on Components, Packaging and Manufacturing Technology, vol. 3, no. 5, pp. 870-879, 2013.

[20] H. Raza and J. Yang, "A low loss rat race balun in gap waveguide technology," in Proceedings of the 5th European Conference on Antennas and Propagation (EUCAP). IEEE, 2011, pp. 1230-1232.

[21] — "Compact uwb power divider packaged by using gap-waveguide technology," in 2012 6th European Conference on Antennas and Propagation (EUCAP). IEEE, 2012, pp. 2938-2942.

[22] A. U. Zaman, J. Yang, and P.-S. Kildal, "Using lid of pins for packaging of microstrip board for descrambling the ports of eleven antenna for radio telescope applications," in 2010 IEEE Antennas and Propagation Society International Symposium. IEEE, 2010, pp. 1-4.

[23] F. Fan, J. Yang, V. Vassilev, and A. U. Zaman, "Bandwidth investigation on half-height pin in ridge gap waveguide," to be published on IEEE Transactions on Microwave Theory and Techniques, 2017. 